\title{
DOES MATE GUARDING PREVENT RIVAL MATING IN SNOW SKINKS? A TEST USING AFLP
}

\author{
Mats Olsson $^{1,2,6}$, Beata Ujvari $^{1}$, Erik Wapstra ${ }^{3}$, Thomas Madsen ${ }^{1}$, \\ Richard Shine ${ }^{4}$, and Staffan Bensch ${ }^{5}$ \\ ${ }^{1}$ University of Wollongong, School of Biological Sciences, NSW 2516, Australia \\ ${ }^{2}$ The University of Göteborg, Department of Zoology, Division of Animal Ecology, \\ Box 463, SE 41390 Göteborg, Sweden \\ ${ }^{3}$ School of Zoology, Locked Bag 5, The University of Tasmania, Hobart 7001, TAS, Australia \\ ${ }^{4}$ University of Sydney, School of Biological Sciences, The Heydon-Laurence Building (A08), \\ NSW 2006, Australia \\ ${ }^{5}$ The University of Lund, Ekologihuset, Helgonavägen 5, SE 22362 Lund, Sweden
}

\begin{abstract}
AвsтRACT: We report on likely mixed paternity in a natural population of snow skinks (Niveoscincus mirolepidotus) from alpine Tasmania, Australia. This species is nonterritorial and males guard females after copulation, suggesting that guarding behavior has evolved to prevent rival mating of still-receptive females. To what degree does this mate-guarding prevent rival copulations? We sampled gravid females at random in the wild and looked for within-clutch mixed paternity among their offspring using amplified fragment length polymorphism (AFLP). Incorporating all visualized fragments, offspring band-sharing based on maternal bands was $0.94( \pm 0.05, \mathrm{SD})$, whereas for paternal fragments it was $0.54( \pm 0.46, \mathrm{SD})$. We then tested paternal band-sharing scores for all young of pairs against the mean score of the maternally inherited fragments to assess whether paternal genetic variation was larger than for a known single parent, hence, suggesting multiple sires. To reduce the risk of unequal sampling of polymorphic maternal and paternal fragments, we based our statistical tests on heterozygous bands only. Offspring band sharing based on maternal heterozygous fragments was on average $0.68( \pm 0.22, \mathrm{SD})$, versus $0.35( \pm 0.33, \mathrm{SD})$ based on paternally inherited fragments. In six of eight clutches $(75 \%)$, at least one pair of young in a clutch had paternal scores outside of the confidence interval for a single parent (i.e., the mother). Thus, mixed paternity seems to be widespread in this population, despite prolonged postcopulatory mate-guarding by males.
\end{abstract}

Key words: AFLP; Lizards; Mate guarding; Multiple paternity

Most Sexual, and some asexual, organisms have their lives dictated by some form of selection arising from female promiscuity. Through this behavior, ejaculates become mixed in the oviducts and rival spermatozoan phenotypes compete to fertilize the eggs (Birkhead and Møller, 1998; Olsson and Madsen, 1998). To reduce this risk, males of many species guard their recently-mated partners. This behavior was one of the first behavioral adaptations to be interpreted in the context of sperm rivalry (e.g., reviews in Devine, 1984; Smith, 1984). Because mateguarding restricts the male's involvement in other activities that may contribute to his lifetime reproductive success, we expect selection to adjust the duration and intensity of the guarding process in relation to expected fitness gains. Available data support this prediction. For example, male snow skinks (Niveoscincus

\footnotetext{
${ }^{6}$ Correspondence: e-mail, molsson@uow.edu.au
}

microlepidotus) scent-trail their mated partners only until the female ovulates, at which point the risk of competition from a rival's sperm disappears (Olsson and Shine, 1998).

Although behaviors such as mate-guarding have long been interpreted as adaptations to selection of sperm from rival males within the oviduct (e.g., Stearns, 1987), the development of molecular markers now allows this scenario to be tested in natural populations. Such studies have revealed an unexpectedly high incidence of paternity by extra-pair males in many taxa (Birkhead and Møller, 1998), and by males never observed with females in species without prolonged pair bonds, such as many species of lizards and snakes (Gullberg et al., 1997; Olsson and Madsen, 1998). Although relatively few studies of paternity have been performed in natural lizard and snake populations, recent work has demonstrated that incidence of mixed paternity can be very high (80\% of clutches in Lacerta agilis, Gullberg et al., 1997; and Uta stansburiana, Zamudio 
and Sinervo, 2001), and covary with incidence of polyandry among populations (17-80\% in Vipera berus, Höggren and Tegelström, 1995; Tegelström and Höggren, 1994). Furthermore, species such as the garter snake (Thamnophis sirtalis), which transfer cloacal plug secretions at copulation, and thus were believed to have evolved the perfect 'chastity belt' (Devine, 1977; Shine et al., 2000), were revealed to have mixed paternity in $50-72 \%$ percent of sampled clutches in some populations (Schwartz et al., 1989; but see Shine et al., 2000). Thus, multiple mating resulting in mixed paternity appears to be widespread in squamate reptiles.

Because of the limited numbers of reptilian studies, the consequences for paternity-assurance behaviors (like mate-guarding) for the incidence of mixed paternity remain unclear. In the present study, we investigate to what degree snow skinks, that exhibit male mate guarding for up to 29 days (Olsson and Shine, 1998), also show evidence of mixed paternity. Thus, our aim is to infer the effectiveness of mate guarding within a natural population.

\section{Materials and Methods Sampling of DNA}

In November 1996, nine females from a natural population were sampled at random from our study population at the summit of Mt. Wellington, Tasmania, Australia, and kept at our laboratory facilities until parturition (husbandry techniques have been described elsewhere: Olsson and Shine, 1998). Females and newborn young were sampled for DNA. The samples were lyophilised, homogenised, and dissolved in $100 \mathrm{mM}$ Tris-EDTA buffer. Whole DNA was isolated by phenolchloroform extraction (Sambrook et al., 1989).

\section{AFLP (Amplified Fragment Length Polymorphism) Procedure}

AFLP was predicted by leaders in the field of molecular ecology to become of 'great use in paternity and mating system studies' because of the high number of loci assayed-much higher than in microsatellites (Baker, 2000; Ritland and Ritland, 2000). For instance, Krauss (1999) unambiguously assigned 242 of $252(96 \%)$ progeny in a natural population of the plant Persoonia mollis (Proteaceae), using three primers that generated 125 polymorphic AFLP loci. However, AFLP, like any paternity assignment technique, sometimes fails. A recent careful assessment of its accuracy, and how it compares to microsatellites, was conducted by Bonin et al. (2004). The intention of these authors was to encourage routine assessment of error rates on genotyping in all published work, stemming from the authors' concern with mis-assignment in paternity studies using microsatellites (primarily due to allelic dropout, e.g., see Gagneux et al., 1997, versus Constable et al., 2001). Bonin et al.'s (2004) assessment of three microsatellite case studies showed an error rate of $0.8-2.0 \%$. Corresponding reassessment of two AFLP studies showed error rates of $2.0 \%$ and $2.6 \%$. Thus, the accuracy of the two techniques seems high and very similar.

The AFLP-PCR technique enables screening of many different regions distributed randomly throughout the genome, and in the present study it was used to identify withinbrood levels of paternity. Fluorescence AFLP protocol was employed following the procedures described by Vos et al. (1995) with minor modifications (Bensch et al., 2002). DNA was digested with EcoRI and MseI (rare- and frequent-cutter enzymes, respectively). Specific double-stranded adapters were ligated to the cutting sites, altering the recognition sequence and preventing a second restriction. Pre-selective amplification was performed with one selective base on each primer (EcoRI-T, and MseI-C), reducing the number of displayed fragments.

Eighteen different selective amplifications were performed using primers with an additional two-base extension. Fragments were visualized by labelling the selective EcoRI primer with a fluorescent dye. Each selective primer combination amplified $\approx 50$-150 fragments in the range of 100-500 bp from each specimen. From the 18 primer combinations the most variable primer that did not show sex linkage (MseI GC EcoRI* and CT) was selected to genotype the females and their offspring.

\section{Assignment of Paternity}

We assigned one aspect of paternity only, namely whether all offspring in the same litter 
was likely to have the same father: that is, does female polyandry result in multiple paternity with more than one male siring the offspring?

To be able to make this assessment without having blood-sampled the male population, we used maternal fragments as our standard for offspring band sharing within a clutch for a single sire (i.e., estimated by the maternally inherited bands). Thus, we hypothesized that if offspring band-sharing based on paternal fragments vary more than corresponding maternal scores (set by a 95\% confidence interval), we would accept paternity as mixed. In order to make this comparison without bias, however, we need to know that we are not basing our band-sharing scores on an unequal representation of homozygous and heterozygous fragments from males and females, respectively. Although AFLP fragments may not follow strict Mendelian inheritance, maternal fragments not present in all offspring behave as heterozygotes (as opposed to those present in all offspring, i.e., homozygotes), hence, our choice of terminology. If maternal bands were to be removed before paternal fragments were scored, the remaining paternal fragments would probably be over-represented by heterozygotic fragments (because homozygotic bands shared by the male and female would already have been removed). To minimise this effect, we calculated two separate estimates of band-sharing: a descriptive score based on all male and female fragments, and a heterozygous 'analytical' score based only on fragments that at least one young in the clutch was lacking. The latter criterion will effectively remove all female homozygous bands, because only female heterozygous bands will show up as polymorphic in a brood.

We calculated genetic similarity between offspring using Wetton et al.'s (1987) similarity index $\mathrm{S}=2 \mathrm{~N}_{\mathrm{AB}} /\left(\mathrm{N}_{\mathrm{A}}+\mathrm{N}_{\mathrm{B}}\right)$, where $\mathrm{N}_{\mathrm{AB}}$ represents the number of bands that two offspring have in common, and $\left(\mathrm{N}_{\mathrm{A}}+\mathrm{N}_{\mathrm{B}}\right)$ equals their summed number of bands. For each pair of offspring, we then tested whether their band-sharing score based on heterozygous unique paternal bands differed from the mean band-sharing score of heterozygous unique maternal bands ('Comparison of a single observation with a mean of a sample', Sokal and Rohlf, 1981, p. 231).

\section{RESUlts}

Averaged over all fragments, band sharing of an offspring's maternally-inherited fragments was $0.94( \pm 0.05, \mathrm{SD})$, whereas band sharing on paternal fragments was on average 0.54 $( \pm 0.46, \mathrm{SD})$. However, as outlined above, this gross difference in band sharing scores from maternal versus paternal inheritance is likely to be partly explained by an overrepresentation of paternal fragments that were polymorphic. When the homozygous fragments were removed, the average band-sharing score declined for both maternally and paternally based scores (with a corresponding increase in variance), but the relative difference between these scores was still almost twice as high for paternally inherited as maternally inherited heterozygous fragments. Offspring bandsharing based on maternal fragments was 0.68 ( $\pm 0.22, \mathrm{SD})$, whereas the corresponding paternal score was $0.35( \pm 0.33, \mathrm{SD}$; Table 1$)$.

Of the nine clutches, eight exhibited both maternally and paternally inherited unique heterozygous fragments (Table 1). Of these eight clutches, six contained at least one sibcomparison with band-sharing scores outside of the maternal $95 \%$ confidence interval (Fig. 1; clutch 5 did not contain both unique maternal and paternal heterozygous fragments, Table 1 ; $t$-test, comparison of a single observation with a mean of a sample, critical $t=2.1$ ). Thus, even with the conservative restriction of our analysis to heterozygous fragments, $75 \%$ of the clutches seemed to be sired by more than one male.

\section{DisCUSSION}

Recent studies of paternity in natural populations of squamate reptiles have demonstrated high levels of mixed paternity, ranging from 17 to $80 \%$ (Olsson and Madsen, 1998). Considering that several of these species exhibit paternity guards such as copulatory plugs (Devine, 1977; Olsson and Madsen, 1998), this high incidence of mixed paternity is somewhat surprising. Snow skinks are no exception in that regard. Our behavioral studies have revealed that male snow skinks guard a not-yet ovulated female with which they have mated, and will scent-trail to find and guard her until she has ovulated (Olsson and Shine, 1998). This behavior may continue for a month, 
TABLE 1.-Banding patterns of offspring screened by AFLP are given for each litter. Maternal bands are the number of unique maternal bands when the bands shared with the siring males are removed (64\%); total number of maternal bands are given within parentheses. Number of bands per offspring includes number of strictly maternal and paternal bands (maternal bands removed) (young denoted Y1 to Yn). The corresponding number of paternal bands are also listed. Band sharing between pairs of individual offspring are followed by the corresponding band sharing score based on heterozygous bands only after the slash (on which Figure 1 is based).

\begin{tabular}{|c|c|c|c|c|c|c|c|}
\hline \multirow{2}{*}{$\begin{array}{l}\text { Female } \\
\text { No. }\end{array}$} & \multirow{2}{*}{$\begin{array}{c}\text { Maternal } \\
\text { bands }\end{array}$} & \multicolumn{2}{|c|}{ No. of bands per offspring } & \multirow{2}{*}{$\begin{array}{l}\text { Paternal } \\
\text { bands }\end{array}$} & \multicolumn{3}{|c|}{ Offspring band sharing (all bands/heterozygous bands) } \\
\hline & & Maternal & Paternal & & M-bands & Focal Young & P-bands \\
\hline 1 & $8(22)$ & $12: 13$ & $5: 13$ & 14 & $0.95 / 0.50$ & $\mathrm{Y} 1-\mathrm{y} 2$ & $0.44 / 0.0$ \\
\hline \multirow[t]{3}{*}{2} & $9(25)$ & $13: 11: 15$ & $9: 7: 22$ & 25 & $0.86 / 0.50$ & $\mathrm{Y} 1-\mathrm{Y} 2$ & $0.75 / 0.88$ \\
\hline & & & & & $0.93 / 0.40$ & $\mathrm{Y} 1-\mathrm{Y} 3$ & $0.39 / 0.0$ \\
\hline & & & & & $0.93 / 0.22$ & Y2-Y3 & $0.34 / 0.09$ \\
\hline \multirow[t]{3}{*}{3} & $5(15)$ & $9: 9: 8$ & $3: 6: 6$ & 9 & $0.93 / 0.66$ & Y1-Y2 & $0.44 / 0.67$ \\
\hline & & & & & $1.00 / 0.57$ & Y1-Y3 & $0.44 / 0.0$ \\
\hline & & & & & $1.00 / 0.43$ & Y2-Y3 & $0.50 / 0.0$ \\
\hline 4 & $15(41)$ & $13: 11$ & $6: 4$ & 9 & $0.79 / 0.82$ & Y1-Y2 & $0.20 / 0.0$ \\
\hline 5 & $8(21)$ & $13: 13$ & $2: 5$ & 6 & $0.98 /-$ & Y1-Y2 & $0.28 /-$ \\
\hline \multirow[t]{3}{*}{6} & $4(12)$ & $5: 4: 5$ & $10: 7: 11$ & 15 & $1.00 / 1.00$ & Y1-Y3 & $0.76 / 0.44$ \\
\hline & & & & & $0.93 / 0.44$ & Y1-Y2 & $0.47 / 0.31$ \\
\hline & & & & & $0.93 / 0.89$ & $\mathrm{Y} 2-\mathrm{Y} 3$ & $0.56 / 0.33$ \\
\hline \multirow[t]{3}{*}{7} & $9(25)$ & $9: 8: 8$ & $7: 7: 8$ & 9 & $0.96 / 0.96$ & Y1-Y2 & $0.86 / 0.50$ \\
\hline & & & & & $0.96 / 0.96$ & Y1-Y3 & $0.93 / 0.67$ \\
\hline & & & & & $0.92 / 0.92$ & Y2-Y3 & $0.80 / 0.0$ \\
\hline 8 & $11(30)$ & $13: 12$ & $6: 7$ & 7 & $0.94 / 0.92$ & $\mathrm{Y} 1-\mathrm{Y} 2$ & $0.92 / 0.0$ \\
\hline \multirow[t]{6}{*}{9} & $13(37)$ & $18: 15: 16: 18$ & $3: 4: 6: 3$ & 9 & $0.92 / 0.76$ & Y1-Y2 & $0.86 / 0.91$ \\
\hline & & & & & $1.00 / 0.70$ & $\mathrm{Y} 1-\mathrm{Y} 4$ & $0.67 / 0.83$ \\
\hline & & & & & $1.00 / 0.70$ & $\mathrm{Y} 2-\mathrm{Y} 4$ & $0.67 / 0.73$ \\
\hline & & & & & $0.90 / 0.70$ & $\mathrm{Y} 1-\mathrm{Y} 3$ & $0.22 / 0.50$ \\
\hline & & & & & $0.94 / 0.70$ & $\mathrm{Y} 2-\mathrm{Y} 3$ & $0.22 / 0.28$ \\
\hline & & & & & $0.94 / 0.63$ & $\mathrm{Y} 4-\mathrm{Y} 3$ & $0.22 / 0.25$ \\
\hline
\end{tabular}

suggesting that a male accepts what appears to be relatively high costs (in terms of time investment, increased exposure to predators, etc.) for a reward that appears relatively trivial in terms of Darwinian fitness. There could be several underlying reasons for this. (1) "Mate guarding" may confer alternative fitness benefits, because a mate-guarding male can simultaneously forage, locate predators, etc. Thus, the fitness gain from sexual selection processes may be combined with other benefits of philopatry. (2) Extra-pair paternity might be even higher than currently occurs if males did not mate-guard; that is, it may be effective to some degree. (3) Continued male attendance may accelerate the female's reproductive cycle, as it does in sand lizards (Lacerta agilis): females emerging from hibernation become receptive more quickly with a male present than when kept singly in captivity (Olsson and Madsen, 1996). Thus, the time a male is associated with the female may influence the rate at which she progresses through her ovarian cycle, thereby reducing the time she is available for copulations with rivals.
Despite these potential accessory benefits from mate-guarding, our data show that this behavior is not $100 \%$ effective in preventing extra-pair copulations. Thus, sperm competition will occur in this species. How robust is our analysis? Admittedly, it rests on the assumption that matings between heterozygous and homozygous males and females are equally common; to the best of our knowledge, there is no reason to believe otherwise. Secondly, litter sizes are small and our analysis therefore more susceptible to sampling biases than when litters are large. However, AFLP is a technique with a low error rate and our intention has not been to assign paternity in the current study, only to assess a mating system parameter-multiple paternity. From this perspective, the risk of erroneous genotyping (ca. 2\%), with no reason to expect any difference in this probability between the sexes, the answer to our rather simple question - how frequent is multiple paternityseems robust and estimated to occur in about three cases out of four. Furthermore, our findings are in close agreement with those of 


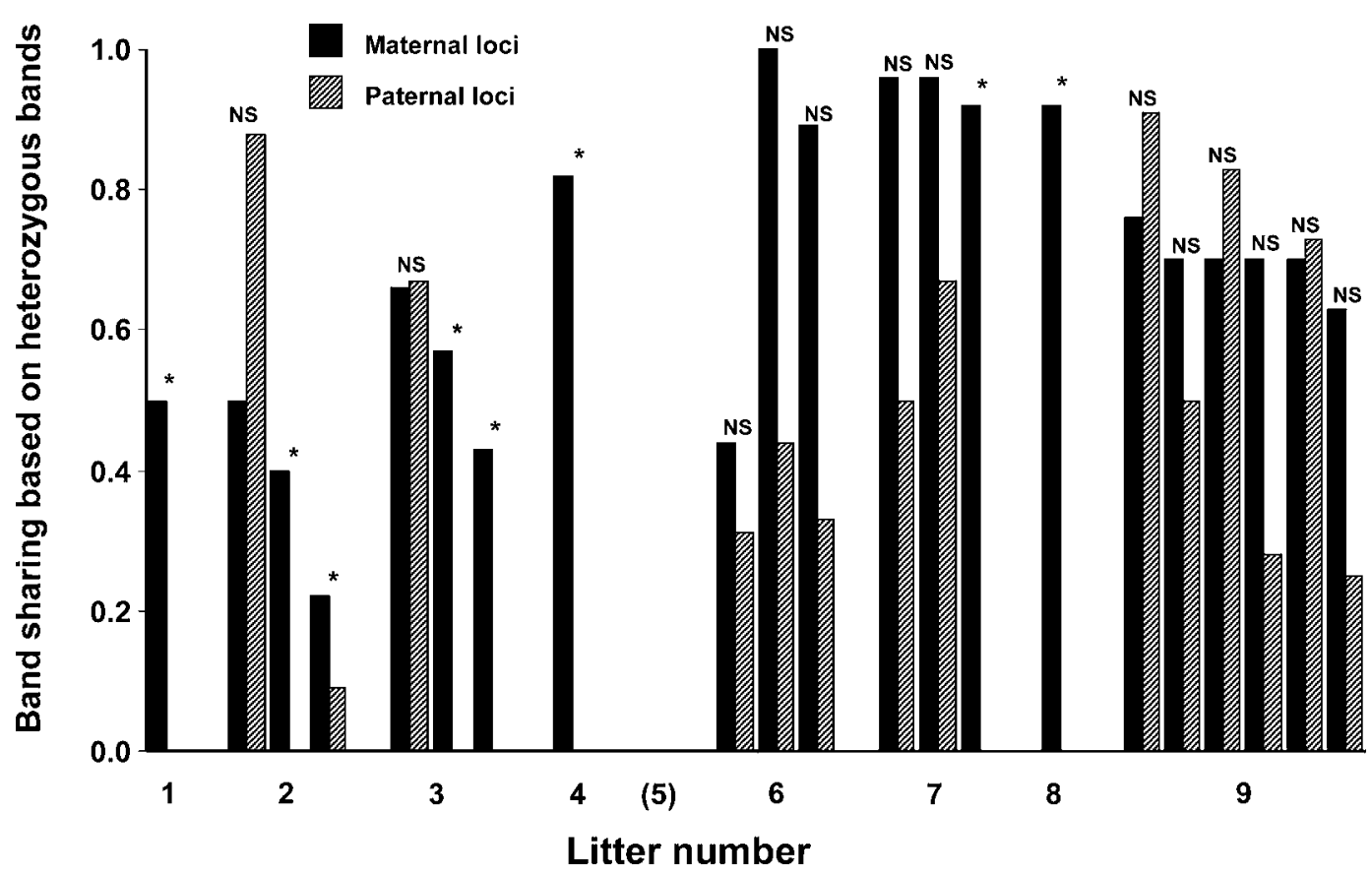

FIG. 1.-Sibling band-sharing based on heterozygous paternally versus maternally inherited fragments. Asterisks denote significant differences between maternally and paternally derived band-sharing scores at $P=0.05$. Thus, significantly lower band sharing based on paternal fragments suggests more than one sire in six out of eight clutches.

Morrison et al. (2002) for another skink species (Eulamprus heatwolei) that exhibits the same kind of polygynandrous, nonterritorial mating system as snow skinks. Their estimate of the frequency of mixed paternity for $E$. heatwolei was $67 \%(n=17)$, which was similar to our estimate of $75 \%$ for N. microlepidotus. Morrison et al.'s study was more extensive than our own, being based on a microsatellite technique using DNA sampled from potential fathers and known mothers and offspring. Four other studies of paternity using molecular markers in lizards with similar nonterritorial mating systems as in snow skinks have also come to the conclusion that extra-pair paternity is frequent (Abell, 1997; Bull et al., 1998; Gullberg et al., 1997; Lewis et al., 2000). This is the case even in the scincid lizard Tiliqua rugosa, which shows unusually long pairbonds that may last several years (Bull et al., 1998).

In summary, our study provides additional support to the growing view that reptilian mating systems incorporate significant postcopulatory effects on reproductive success.
The wide diversity in reptilian mating systems suggests that these animals should serve as ideal models for studies of factors that influence paternity subsequent to copulation.

Acknowledgments.-The Australian Research Council, The Swedish Natural Science Research Council, Collianders Stiftelse and The Swedish Institute are gratefully acknowledged for financial support, the Wilkes families for logistics, and T. Helin and L. Bak-Olsson for excellent field assistance.

\section{Literature Cited}

ABELL, A. 1997. Estimating paternity with spatial behavior, and DNA fingerprinting in the striped plateau lizard, Sceloporus virgatus (Phrynosomatidae). Behavioral Ecology and Sociobiology 41:217-236.

BAKER, A. 2000. Molecular Methods in Ecology (reprinted 2002). Blackwell Ltd, Oxford, U.K.

Bensch, S., A. J. Helbig, M. Salomon, and I. Seibold. 2002. AFLP analysis identifies hybrids between two subspecies of warblers. Molecular Ecology 11: 473-481.

Birkhead, T. R., And A. P. Møller. 1998. Sperm Competition and Sexual Selection. Academic Press, London, U.K.

Bonin, A., E. Bellemain, P. Bronken Eidesen, F. Pompanon, C. Brochmann, and P. Taberlet. 2004. 
How to track and assess genotyping errors in population genetics studies. Molecular Ecology 13:3261-3273.

Bull, C. M., S. J. B. Cooper, and B. C. Baghurst. 1998. Social monogamy and extra-pair fertilization in an Australian lizard, Tiliqua rugosa. Behavioral Ecology and Sociobiology 44:63-72.

Constable, J. L., M. V. Ashley, J. Goodall, and A. E. Pusey. 2001. Noninvasive paternity assignment in Gombe chimanzees. Molecular Ecology 10:1279-1300.

Devine, M. C. 1977. Copulatory plugs, restricted mating opportunities and reproductive competition among male garter snakes. Nature 267:345-346.

1984. Potential sperm competition in reptiles; behavioral and physiological consequences. Pp. 509 521. In R. L. Smith (Ed.), Sperm Competition and the Evolution of Animal Mating Systems. Academic Press, Orlando, Florida, U.S.A.

Gagneux, P., D. S. WoOdruff, and C. Boesch. 1997. Furtive mating in female chimpanzees. Nature 387:358-359.

Gullberg, A., M. Olsson, and H. Tegelström. 1997. Male mating success, reproductive success and multiple paternity in a natural population of sand lizards: behavioural and molecular genetics data. Molecular Ecology 6:105-112.

Höggren, M., and H. Tegelström. 1995. DNA fingerprinting shows within-season multiple paternity in the adder (Vipera berus). Copeia 1995:271-277.

Krauss, S. L. 1999. Complete exclusion of non-sires in an analysis of paternity in a natural plant population using amplified fragment length polymorphism (AFLP). Molecular Ecology 8:217-226.

Lewis, A. R., G. Tirado, and J. Sepulveda. 2000. Body size and paternity in a teiid lizard (Ameiva excul). Journal of Herpetology 34:110-120.

Morrison, S. F., J. S. Keogh, and I. A. W. Scott. 2002 Molecular determination of paternity in a natural population of the multiply mating polygynous lizard Eulamprus heatwolei. Molecular Ecology 11:535-545.

Olsson, M., And T. Madsen. 1996. Costs of mating with infertile males selects for late emergence in female Lacerta agilis. Copeia 1996:462-464.

Olsson, M., and T. Madsen. 1998. Sexual selection and sperm competition in reptiles. Pp. 503-564. In T. R. Birkhead and A. P. Møller (Eds.), Sexual Selection and Sperm Competition. Academic Press, London, U.K.

Olsson, M., AND R. Shine. 1998. Chemosensory mate recognition may facilitate prolonged mate guarding by male snow skinks, Niveoscincus mcrolepidotus. Behavioral Ecology and Sociobiology 43:359-363.

Ritland, C., and K. Ritland. 2000. DNA-fragment in plants. Pp. 208-234. In A. Baker (Ed.), Molecular Methods in Ecology. Blackwell Science, Oxford, U.K.

Sambrook, J., E. F. Fritsch, and T. Maniatis. 1989. Molecular Cloning: a Laboratory Manual. Cold Spring Harbor Laboratory, Cold Spring Harbor, New York, U.S.A.

Schwartz, J. M., G. F. McCracken, and G. M. BurghardT. 1989. Multiple paternity in wild populations of the garter snake, Thamnophis sirtalis. Behavioral Ecology and Sociobiology 25:269-273.

Shine, R., M. Olsson, and R. T. Mason. 2000. Chastity belts in gartersnakes: the functional significance of mating plugs. Biological Journal of the Linnean Society 70:377-390.

Sмiтh, R. L. 1984. Sperm competition and the Evolution of Animal Mating Systems. Academic Press, Orlando, Florida, U.S.A.

SOKal, R. R., AND J. M. Rohlf. 1981. Biometry-The Principles and Practice of Statistics in Biological Research. W. H. Freeman and Company, San Fransisco, California, U.S.A.

Stearns, S. C. 1987. The Evolution of Sex and Its Consequences. Birkhäuser Verlag, Basel, Switzerland.

Tegelström, H., and M. Höggren. 1994. Paternity determination in the adder (Vipera berus)—DNA fingerprinting or random amplified polymorphic DNA? Biochemical Genetics 32:249-256.

Vos, P., R. Hogers, M. Bleeker, M. Reijens, T. Lee, M. van de Hornes, A. Frijters, J. Pot, J. Peleman, M. Kuiper, and M. Zabeay. 1995. AFLP: a new technique for DNA fingerprinting. Nucleic Acids Research 23:4407-4414.

Wetton, J. H., R. E. Carter, D. T. Parkin, and D. Walters. 1987. Demographic study of a wild house sparrow population by DNA-fingerprinting. Nature 327:147-149.

Zamudio, K. R., And B. Sinervo. 2001. Polygyny, mateguarding, and posthumous fertilization as alternative male mating strategies. Proceedings of the National Academy of Science 47:14427-14432.

Accepted: 25 July 2005 Associate Editor: Troy Baird 